\title{
EDITORIAL
}

\section{Teaching old drugs new tricks: asthma therapy adjusted by patient perception or noninvasive markers}

\author{
P.G. Gibson
}

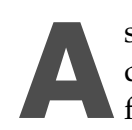
sthma management is having a makeover. Three very different treatment approaches are parading the conference catwalks. Each uses long-acting $\beta$-agonists (LABA) and inhaled corticosteroids (ICS) as the basis of maintenance therapy. However, they differ substantially in how the treatment is adjusted, and in what outcomes have been reported. One approach advocates escalating ICS doses to achieve physician-assessed symptom control [1] and has recently been reviewed in the European Respiratory Journal [2]. Another advocates the use of objective markers of airway inflammation (induced sputum, airway hyperresponsiveness) to adjust treatment $[3,4]$, and the third approach lets the patient off the leash to use LABA/ICS as needed for short-term symptom management [5].

\section{HOW DO THEY COMPARE, AND SHOULD THEY REPLACE TRADITIONAL GUIDELINES?}

The limitations of our current treatment approaches for asthma are well known [6], and each of these new approaches has been found to be superior to their comparator in well-conducted randomised controlled trials. So, there is a sense of optimism and excitement surrounding these different approaches to asthma management. But do they constitute a new summer frock, working with and enhancing what we have, or are they more like cosmetic surgery, artificially covering a decay in asthma management that results from a mismatch between expectation and reality?

Asthma is a variable disease, and exacerbations are responsible for a disproportionate amount of the morbidity and mortality from asthma. Current management approaches have limited efficacy for exacerbations [7]. Doubling ICS doses has not been shown to be effective for exacerbation management [8], and intensive self-management programmes are required to reinforce adherence and reduce exacerbations [9]. Using these approaches, an emergency department visit for asthma can be prevented in one out of every 22 patients who complete an asthma self-management programme (number needed to treat $(N N T)=22)$ [9]. Several limitations to this approach are that physicians seldom provide a written action plan $[6,10]$, and patients may not follow their self-management instructions. For example, in adults, TURNER et al. [11] found that there was between 52 and $65 \%$ adherence to the self-management plan. Furthermore, although patients like the idea of action plans,

CORRESPONDENCE: P.G. Gibson, Dept of Respiratory and Sleep Medicine, Hunter Medical Research Institute, John Hunter Hospital, Locked Bag 1, Hunter Region Mail Centre, New South Wales 2310, Australia. Fax: 61 249855850. E-mail: Peter.Gibson@hunter.health.nsw.gov.au they modify their asthma plan according to their own perceptions and experience of asthma [12]. It is in this context that the study by O'BYRNE et al. [5] challenges our current management approaches in asthma and asks us to take a different approach.

O'BYRNE et al. [5] examined patients who were using inhaled corticosteroid therapy but still had symptomatic asthma and significant reversibility. By Global Initiative for Asthma (GINA) criteria, they had moderate persistent asthma with poor symptom control. They received Symbicort ${ }^{\circledR}$ (budesonide/formoterol) as Maintenance And Reliever Therapy (SMART), and this was compared with budesonide/ formoterol in a fixed dose and with high-dose budesonide. Compared with fixed-dose therapy, there was a significant reduction in exacerbations with SMART. The number of patients who needed to be treated with a SMART approach in order to prevent one severe exacerbation was 11 (table 1).

Noninvasive markers of airway inflammation have been used to adjust therapy in two studies. SONT et al. [3] adjusted maintenance therapy in order to suppress airway hyperresponsiveness in patients with less severe asthma. Over a 2-yr period, the NNT to prevent a mild exacerbation was 5 . GREEN et al. [4] used sputum eosinophilia to adjust maintenance therapy. When compared with an approach based on current guidelines in patients with severe asthma, there was a significant reduction in severe exacerbations. Using a sputumbased approach, the NNT to prevent one severe exacerbation over 12 months was 5 (table 1 ).

\section{ISSUES}

When the treatment for asthma is reviewed, it is important to assess the potential for both overtreatment and undertreatment. The studies using noninvasive markers directly address this by using a treatment algorithm that adjusts doses in accordance with disease parameters. Symptoms of asthma are not specific for the underlying pathophysiological abnormalities [13], and, consequently, clinicians find that there are limitations to using symptoms alone for disease management [4]. In SMART, overtreatment with LABA/ICS could occur if symptoms were misinterpreted or if symptoms were not a sign of an impending exacerbation. We know that upper airway symptoms can be misinterpreted as due to asthma [14]. Similarly, a dysfunctional breathing pattern that is linked to anxiety and panic is frequently mistaken for asthma, and is refractory to asthma therapy [15]. It is estimated to be present in up to one third of females and one fifth of males. This serves 
TABLE 1 Comparison of new treatment approaches for asthma

\begin{tabular}{lccc} 
Study & O'BYRNE et al. [5] & SoNT et al. [3] & GREEN et al. [4] \\
\hline Participants & Moderate persistent asthma & Mild (? persistent) asthma & Severe asthma \\
Sample size $\mathbf{n}$ & 2760 & 75 & 74 \\
Treatment adjustment & SMART & Airway hyperresponsiveness & Sputum eosinophils \\
Outcome & Severe exacerbation & Mild exacerbation & Severe exacerbation \\
Number needed to treat & 11 & 5 & 5 \\
\hline
\end{tabular}

SMART: Symbicort ${ }^{\circledR}$ (budesonide/formoterol) as Maintenance And Reliever Therapy

to reinforce that "all that wheezes is not asthma". It emphasises the need to objectively confirm asthma as the cause of symptoms, and to educate patients in symptom recognition and interpretation. The "suck it and see" approach that is commonly used, where a response to therapy is used to make the diagnosis, must seriously be questioned, since it could easily result in overtreatment of nonasthma symptoms. A second form of overtreatment occurs when LABA/ICS are used for symptoms that do not indicate an impending exacerbation. Based on an analysis of the exacerbations in the Formoterol and Corticosteroids Establishing Therapy (FACET) study, there was increased rescue $\beta_{2}$-agonist use in between 11 and $21 \%$ of occasions that did not result in an exacerbation [16].

Undertreatment of asthma could occur if patients failed to perceive deteriorating asthma. This is a recognised problem in asthma. For example, TATTERSFIELD et al. [16] found that $18 \%$ of exacerbations were associated with a significant fall in lung function, but this was not perceived by the patient, and oral corticosteroids were not used. Perception of airway narrowing is impaired during a mild asthma exacerbation, and this is related to concurrent changes in airway hyperresponsiveness and resting lung function [17]. In the O'BYRNE et al. [5] study, subjects with poor symptom perception would have been excluded by the entry requirement of frequent $\beta_{2}$-agonist use for symptoms. These considerations regarding the undertreatment and overtreatment of asthma caution against using SMART beyond the clear study entry criteria of moderate persistent asthma with poor symptom control despite ICS therapy.

\section{WHY DOES SMART WORK?}

We know that nonadherence is a common problem in asthma, and SMART seems to accommodate this by allowing patients to receive LABA/ICS when they are symptomatic. Therefore, it may work by dealing with adherence. However, nonadherence takes many forms [18]. Unintentional nonadherence (forgetting) could be addressed by SMART, but this approach will not alter reasoned or intentional nonadherence (refusal), or the unwillingness to accept an asthma identity by patients (denial). What would nonadherence with SMART look like? It may manifest as nonattendance at scheduled visits or as undeclared short-acting $\beta_{2}$-agonist use. These other types of nonadherence require alternative approaches and emphasise the importance of the doctor engaging the patient in the management and understanding of their illness.
SMART could also work by resulting in early treatment of exacerbations. Many asthma exacerbations are preceded by a prodrome of deterioration that lasts for 3-5 days [16]. Deteriorating inflammation and hyperresponsiveness are features of asthma exacerbations, and data now show that high-dose ICS work within hours to suppress eosinophilic inflammation in asthma [19], and that LABA rapidly protect against bronchial hyperresponsiveness. Thus, combination LABA/ICS could work by successfully treating these features very early in an exacerbation.

SMART may also act by treating a component of asthma that is associated with frequent exacerbations. In the analysis of the FACET exacerbations [16], those subjects who experienced severe exacerbations often had a deterioration in symptoms or rescue $\beta_{2}$-agonist use that was not followed by a subsequent severe exacerbation. This suggests that patients who experience severe exacerbations have a greater degree of asthma instability in the interval period, which is not adequately controlled by a fixed maintenance dose of LABA/ICS, but may be better managed by SMART. This is likely to represent airway inflammation, and may also be responsible for the success of therapy guided by noninvasive markers [3, 4].

A number of issues remain to be addressed. Patients in all trials continue to experience severe exacerbations and have a requirement for oral corticosteroids. This will need to be accommodated when using SMART, or any of the new approaches. What does the action plan look like when patients use SMART? What happens when asthma is not controlled with SMART, and how should the maintenance dose of LABA/ICS be determined? These latter problems are typically addressed in specialist centres and, based on other data, may be aided by the use of noninvasive markers of inflammation. At present, access to these tests is a limiting factor.

\section{CONCLUSION}

When considering these newer approaches to asthma therapy, clinicians will be looking to see that the benefits can be reproduced in other trials, and asking how the different approaches compare with one another. Specialists should be reinforcing the need for accurate diagnosis of the cause of symptoms, and making available the necessary diagnostic tests to assist in the determination of symptoms. These new approaches to asthma management challenge us all to rethink 
our goals in asthma care, and to review what sort of partnership we will have with the person with asthma who is seeking our help.

\section{REFERENCES}

1 Bateman ED, Boushey HA, Bousquet J, et al. GOAL Investigators Group. Can guideline-defined asthma control be achieved? The Gaining Optimal Asthma Control study. Am J Respir Crit Care Med 2004; 170: 836-844.

2 Reddel HK. Goals of asthma treatment: how high should we go? Eur Respir J 2004; 24: 715-717.

3 Sont JK, Willems LNA, Bel EH, van Krieken JHJM, Vandenbroucke JP, Sterk PJ. Clinical control and histopathologic outcome of asthma when using airway hyperresponsiveness as an additional guide to long-term treatment. The AMPUL Study Group. Am J Respir Crit Care Med 1999; 159: 1043-1051.

4 Green RH, Brightling CE, McKenna S, et al. Asthma exacerbations and sputum eosinophil counts: a randomised controlled trial. Lancet 2002; 360: 1715-1721.

5 O'Byrne PM, Bisgaard H, Godard PP, et al. Budesonide/ formoterol combination therapy as both maintenance and reliever medication in asthma. Am J Respir Crit Care Med 2005; 171: 129-136.

6 Rabe KF, Vermeire PA, Soriano JB, Maier WC. Clinical management of asthma in 1999: the Asthma Insights and Reality in Europe (AIRE) study. Eur Respir J 2000; 16: 802-807.

7 Sin DD, Man J, Sharpe H, Gan WQ, Man SF. Pharmacological management to reduce exacerbations in adults with asthma: a systematic review and metaanalysis. JAMA 2004; 292: 367-376.

8 Harrison TW, Oborne J, Newton S, Tattersfield AE. Doubling the dose of inhaled corticosteroid to prevent asthma exacerbations: randomised controlled trial. Lancet 2004; 363: 271-275.
9 Gibson PG, Powell H, Coughlan J, et al. Self-management education and regular practitioner review for adults with asthma. Cochrane Database Syst Rev 2003; 1: CD001117.

10 Wilson DH, Adams RJ, Appleton SL, et al. Prevalence of asthma and asthma action plans in South Australia: population surveys from 1990 to 2001. Med J Aust 2003; 178: 483-485.

11 Turner MO, Taylor D, Bennett R, Fitzgerald JM. A randomized trial comparing peak expiratory flow and symptom self-management plans for patients with asthma attending a primary care clinic. Am J Respir Crit Care Med 1998; 157: 540-546.

12 Douglass J, Aroni R, Goeman D, et al. A qualitative study of action plans for asthma. BMJ 2002; 324: 1003-1005.

13 Parameswaran K, Pizzichini E, Pizzichini MM, Hussack P, Efthimiadis A, Hargreave FE. Clinical judgement of airway inflammation versus sputum cell counts in patients with asthma. Eur Respir J 2000; 15: 486-490.

14 Goldberg BJ, Kaplan MS. Non-asthmatic respiratory sympomatology. Curr Opin Pulm Med 2000; 6: 26-30.

15 Thomas M, McKinley RK, Freeman E, Foy C, Prodger P, Price D. Breathing retraining for dysfunctional breathing in asthma: a randomised controlled trial. Thorax 2003; 58: 110-115.

16 Tattersfield AE, Postma DS, Barnes PJ, et al. Exacerbations of asthma: a descriptive study of 425 severe exacerbations. The FACET International Study Group. Am J Respir Crit Care Med 1999; 160: 594-599.

17 Salome CM, Leuppi JD, Freed R, Marks GB. Perception of airway narrowing during reduction of inhaled corticosteroids and asthma exacerbation. Thorax 2003; 58: 1042-1047.

18 Sawyer SM, Aroni RA. Sticky issue of adherence. J Paediatr Child Health 2003; 39: 2-5.

19 Gibson PG, Saltos N, Fakes K. Acute antiinflammatory effects of inhaled budesonide in asthma: a randomized controlled trial. Am J Respir Crit Care Med 2001; 163: 32-36. 